\title{
AVALIAÇÃO DO CONTEXTO LABORAL E A QUALIDADE DE VIDA NO TRABALHO DE SERVIDORES PÚBLICOS COM DEFICIÊNCIA
}

Evaluation of the work context and quality of life in the work of civil servers with disabilities

Évaluation du contexte de travail et de la qualité de vie au travail des employés publics

handicapés

Evaluación del contexto laboral y la calidad de vida en el trabajo de funcionarios públicos con discapacidad

Juliana Werneck de Souza ${ }^{1}$

http://orcid.org/0000-0001-6224-5327

Bacharel em Enfermagem. Mestre em Psicologia Social, do Trabalho e das Organizações pela Universidade de

Brasília.

Câmara dos Deputados, Câmara Federal, Brasília, Distrito Federal, Brasil.

Psicólogo do Trabalho, Doutorado em Ergonomia pelo Ecole Pratique des Hautes Etudes, França $\begin{array}{r}\text { Mário Cesar Ferreira }^{2} \\ \text { http://orcid.org/0000-0002-4962-5154 }\end{array}$

(1998).

Universidade de Brasília, Brasília, Distrito Federal, Brasil.

\section{Resumo}

O estudo buscou conhecer a percepção de servidores públicos com deficiência em relação a seu contexto labo ral e a qualidade de vida no trabalho, sob a perspectiva da inclusão e da ergonomia da atividade. Foram realizadas 25 entrevistas semiestruturadas e os dados submetidos à análise léxica do discurso, com suporte do software IRaMuTeQ. Verificou-se a coexistência de representações de bem-estar e mal-estar, com certa predominância de representações de bem-estar. Observa-se bem-estar quando a organização do trabalho permite certo grau de autonomia, liberdade e flexibilidade, quando as relações socioprofis sionais são harmoniosas, quando há espaço de fala e deliberação, quando existem oportunidades de crescimento profissional, aprendizagem e reconhecimento, equilíbrio entre vida pessoale profissional e quando a chefia oferece suporte e promove a inclusão. O mal-estar se manifesta quando há falta de condições de trabalho, sobrecarga de tarefas, pressão por prazos, desconsideração às necessidades individuais, falta de espaço de diálogo. Em relação a aspectos relacionados à deficiência, os mais críticos foram a percepção de falta de oportunidades de ascensão pelos servidores cegos e pelos servidores com jornada especial reduzida. O estudo forneceu pistas para novas investigações e subsídios aos gestores para mudanças organizacionais no contexto pesquisado.

Palavras-chave: Qualidade de Vida no trabalho; Deficiência; Contexto de trabalho; Serviço Público.

Abstract
$\begin{aligned} & 1 \text { julianawsouza@gmail.com } \\ & 2 \text { ferreiramariocesar@gmail.com }\end{aligned}$

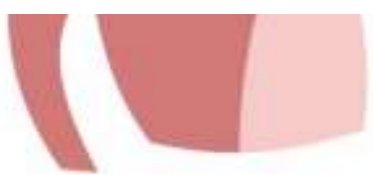

2 ferreiramariocesar@gmail.com 
The study sought to understand the perception of civil servers with disabilities, related to labor context and quality of life at work, from the perspective of inclusion and the ergonomics of the activity. Twenty-five semi-structured interviews' data were submitted to speech lexical analys is with support from the IRaMuTeQ software. There were coexistence of representations of well-being and malaise. It is observed well-being when the organization of work allows a certain degree of autonomy, freedom and flexibility, when the socio-professional relations are harmonious, when there is space for speech and deliberation, when there are opportunities for professional growth, learning and recognition, balance between life personal and professional and when the management supports and promotes inclusion. The malaise is seen when there is a lack of working conditions, overloading of tasks, pressure for deadlines, dis regard of individual needs, lack of space for dialogue. Regarding aspects related to dis ability, the most critical were the perception of lack of opportunities for ascension by blind servers and by servers with reduced special working hours. The study provided clues to further investigations and subsidies to managers for organizational changes in the context.

Keywords: Quality of life at work; Disability; Context of work; Public Service.

\section{Résumé}

Le but de la recherche a été de connaître les representations des employés publics handicapés en ce qui concerne leur contexte de travail et la la qualité de vie au travail dans une perspective de l'inclusion et de l'ergonomie de l'activité. Les données de 25 entretiens ont été analysés avec l'aide du logiciel IRaMuTeQ. On a observé une prévalence de vécus de bien-être parmi les participants lorsque il s'agit de l'organisation du travail qui sont liées aux représentations d'autonomie au travail et de flexibilité dans ce cas elles sont associées aux représentations de rapports sociaux harmonieux, des oportunités de croissance professionnelle, de reconnaissance au travail, et de soutien organis ationnel. Le mal-être est apparu lorsque les conditions de travail sont faibles, il y a de surcharge de travail, exigences de délais, non prise en compte les besoins individuels, il n’y pas de possibilités de dialogues. Par rapport les aspects liés aux handicaps, les plus critiques ont été le manque d’opportunités pour la croissance professionnelle des employes aveugles et aussi par ceux qui ont de journées de travail reduites. La recherche a fourni de pistes pour nouvelles investigations et des apports aux gestionnaires vers des changements organisationnels dans le contexte etudié.

Mots clés: Qualité de Vie au Travail; Handicaps; Contexte de travail; Employes Publics.

\section{Resumen}

El estudio buscó conocer la percepción de funcionarios públicos con discapacidad en relación a su contexto laboral y la calidad de vida en el trabajo, desde la perspectiva de la inclusión y la ergonomía de la actividad. Los datos de 25 entrevistas semiestructuradas fueron sometidos al análisis léxico del discurso, con soporte del software IRaMuTeQ. Se verificó la coexistencia de representaciones de bienestary malestar. Se observa el bienestar cuando la organización del trabajo permite cierto grado de autonomía, libertad y flexibilidad, cuando las relaciones socioprofesionales son armoniosas, cuando hay espacio de habla y deliberación, cuando existen oportunidades de crecimiento profesional, aprendizaje y reconocimiento, equilibrio entre vida personal y profesional y cuando la jefatura ofrece soporte y promueve la inclusión. El malestar se manifiesta cuando hay falta de condiciones de trabajo, sobrecarga de tareas, presión por plazos, desconsideración a las necesidades individuales, falta de espacio de diálogo. En cuanto a aspectos relacionados a la discapacidad, los más críticos fueron la percepción de falta de oportunidades de ascenso por los servidores ciegos y por los servidores con jornada especial reducida. El estudio proporcionó pistas para nuevas investigaciones y subsidios a los gestores para cambios organizacionales en el contexto investigado.

Palabras clave: Calidad de vida en el trabajo; Discapacidad; Contexto de Trabajo; Servicio Publico.

INTRODUÇÃO

Estima-se que 23,9\% da população brasileira, que corresponde a mais de 40 milhões de pessoas, apresente alguma deficiência ou limitação funcional (Brasil, 2012). Uma parcela importante, cerca de 6,5 milhões de pessoas, encontra-se na chamada "idade produtiva" (Garcia, 
2014), o que justifica a preocupação e o interesse governamental, empresarial, social e acadêmico em saber como se dará a inserção desse grupo de pessoas no mercado de trabalho. Ademais, o Brasil é signatário da Convenção Internacional dos Direitos da Pessoa com Deficiência, que no Brasil tem força constitucional e onde recentemente foi sancionada a Lei Brasileira de Inclusão ou Estatuto da Pessoa com Deficiência (Lei 13.246/2015), que possui um capítulo inteiro dedicado ao tema do trabalho. A extensão do arcabouço legal brasileiro destinado a proteger direitos e fornecer garantias às pessoas com deficiência ( $\mathrm{PcD}$ ) parece indicar, de um lado, a preocupação com o bem-estar e a integridade do grupo, de outro a dificuldade de que a inclusão socioprofissional realmente se efetive. Parte das dificuldades de efetiva inclusão nos contextos de trabalho é relacionada ao desconhecimento das reais capacidades de desempenho das PcD e a crenças de gestores e profissionais que associam deficiência à incapacidade ou invalidez (Bahia, 2006; Bortman, Locatelli, Bandini \& Rebelo, 2015; Sassaki, 2010).

Não existe um consenso acerca do conceito de deficiência, que varia de acordo com a perspectiva e o foco de análise adotados pelos autores (Carvalho-Freitas, Leal \& Souto, 2011). Neste trabalho será utilizada a definição presente no artigo $2^{\circ}$ da LBI (Brasil, 2015), considerando-se o contexto social do trabalho: "Pessoa com deficiência é aquela que tem impedimento de longo prazo de natureza física, mental, intelectual ou sensorial, o qual, em interação com uma ou mais barreiras, pode obstruir sua participação plena e efetiva na sociedade em igualdade de condições com as demais pessoas".

As PcD podem ser consideradas pessoas "diversas" ou "minorias", definidas como pertencentes a grupos "tradicionalmente sub-representados nas organizações, em termos de poder, prestígio e status", conforme propõem Hanashiro, Torres, Ferdman e D’Amario (2011, p. 2). A diversidade nas organizações tem sido defendida como um valor organizacional. Os autores constatam, contudo que, para se alcançar efetividade organizacional com uma força de trabalho diversa, o clima organizacional precisa ser adequado e a inclusão precisa ser ativamente fomentada, uma vez que não se trata de um comportamento espontâneo das pessoas.

Importante problematizar o fato de que, na prática, a gestão da diversidade e a inclusão nas organizações, buscam integrar duas racionalidades a priori antagônicas e com objetivos distintos: a razão econômica - prevalente - e a razão sociocultural, que busca superar práticas discriminatórias e promover o ideal da diferença como inerente ao humano e positivo para o mercado de trabalho (Ribeiro \& Ribeiro, 2010). Os autores apontam que muitas vezes a inclusão de PcD se manifesta mais como discurso e estratégia de marketing, e menos como prática 
organizacional efetiva. Desse modo, assistimos a uma prevalência de uma lógica instrumental sobre a lógica do compromisso social.

Sassaki (2010) conceitua inclusão como adequação dos ambientes para toda e qualquer pessoa desenvolver plenamente sua cidadania. Salienta tratar-se de um processo de transformação social baseado em princípios como aceitação das diferenças, convivência com a diversidade e aprendizagem por meio da cooperação. Esse preceito coaduna-se com um princípio fundamental da ergonomia da atividade (EA) que é "adaptar o trabalho ao trabalhador". Ferreira \& Antloga (2012) afirmam ser um "imperativo ético" fundamental ao caráter antropocêntrico da EA, adaptar, ajustar e compatibilizar a lógica de funcionamento do contexto de trabalho às pessoas, como forma de garantir o bem-estar dos indivíduos e a efetividade organizacional. Esse aspecto encontra-se em total sintonia com o paradigma da inclusão.

Ferreira (2011) critica a concepção dominante dos estudos de Qualidade de Vida no Trabalho (QVT) no Brasil, com foco dominante nos indivíduos, em ações paliativas de caráter assistencialista, com objetivo prioritário de garantia da produtividade, em detrimento do bemestar do trabalhador, caracterizando uma atuação essencialmente produtivista. Propõe a "Ergonomia da Atividade" como alternativa teórico-metodológica de diagnóstico e intervenção, por meio de uma inversão de perspectiva que contempla um viés preventivo, buscando atuar nas causas do mal-estar e com foco no contexto organizacional, e não no indivíduo como "variável de ajuste". A Ergonomia da Atividade Aplicada à Qualidade de Vida no Trabalho - EAA_QVT (Ferreira, 2012) orienta a produção do conhecimento científico, considerando a relação entre indivíduo e ambiente (contexto sociotécnico) mediado pela atividade de trabalho.

Com o objetivo de conhecer como servidores com deficiência de uma organização pública do legislativo federal localizada na cidade de Brasilia avaliam seu contexto de trabalho, em aspectos relacionados à QVT, realizou-se um estudo de caso, de natureza empírica, exploratória e descritiva (Demo, 2000). A abordagem qualitativa utilizada não pretende a generalização de resultados, mas ao aprofundamento da compreensão de um grupo social específico, no contexto de uma organização (Goldenberg, 2009). Em razão da forma de análise dos dados, descrita adiante, considera-se que este seja um estudo qualitativo, com enfoque quantitativo. 


\section{MATERIAIS E MÉTODOS}

Para a realização da pesquisa, obteve-se autorização prévia da direção do órgão. A coleta de dados contou com as seguintes etapas: (a) Contato com a Coordenação de Acessibilidade da organização; (b) Envio do convite virtual para participação na pesquisa; (c) Reforço do convite virtual duas semanas após o envio do primeiro; (d) Contato com participantes, via e-mail, para agendamento das entrevistas no local de trabalho, em horário e local de conveniência para os participantes; (e) Entrevistas propriamente ditas, após rapport inicial e assinatura de Termo de Consentimento Livre e Esclarecido (TCLE). Utilizou-se, portanto, parcialmente os recursos metodológicos habitualmente empregados na Análise Ergonômica do Trabalho (AET).

O período de realização das 25 entrevistas semiestruturadas $(n=25)$ ocorreu entre 23 de março e 30 de maio de 2017. A duração média foi de 79 minutos, sendo a mediana de 65 minutos. Todos os participantes autorizaram gravação das entrevistas. A amostra de conveniência representou $39 \%$ do universo de servidores com deficiência considerado na pesquisa.

$\mathrm{Na}$ fase de análise dos dados, os segmentos de textos e as respectivas discussões que poderiam identificar os respondentes foram submetidas previamente aos participantes e discutiu-se com eles a adequação e a pertinência de explicitar e discutir o tema. Dessa forma, procurou-se manter fidelidade ao acordado nos TCLE e ao paradigma da pesquisa emancipatória e participativa, em que se busca ressignificar o papel do participante, como "sujeito" de pesquisa, e não "objeto" de pesquisa, sendo consultado e envolvido, na medida que a questão afeta sua vida (Stalker, 1998, citado por Watson, 2012).

As entrevistas foram transcritas e os trechos classificados em categorias analíticas prédefinidas, de acordo com o roteiro e o referencial teórico-metodológico, para formarem corpus específicos e serem submetidos à análise pelo software IRaMuTeQ, (Camargo \& Justo, 2013). Trata-se de uma técnica computadorizada de análise textual baseada em cálculos da coocorrência de palavras em segmentos de texto. O pressuposto é que as palavras não se distribuem ao acaso no texto (Ferreira \& Antloga, 2012). O software IRaMuTeQ apresenta rigor estatístico e permite aos pesquisadores utilizarem diferentes recursos técnicos de análise lexical, desde os mais simples, como o cálculo de frequência, até análises multivariadas, como a classificação hierárquica descendente (CHD)/ALCESTE. Um benefício da análise lexical, apontado pelos autores é a superação da clássica dicotomia entre quantitativo e qualitativo na análise de dados (Camargo \& Justo, 2013a). 


\section{Perfil Amostral}

O perfil dos participantes consiste sinteticamente em quantitativo equilibrado de homens $(\mathrm{n}=13 ; 52 \%)$ e mulheres $(\mathrm{n}=12 ; 48 \%)$; idade média de 44 anos; predominantemente de cor branca, casados e em união estável. Todos possuem escolaridade de nível superior, sendo que $60 \%$ ( $n=15)$ possui pós-graduação (especialização, mestrado ou doutorado) e dos 10 que possuem apenas graduação, um deles tem duas graduações e está cursando mestrado. Quanto aos tipos de deficiência (Figura 1), a maioria tem deficiência física, seguida de visual e auditiva. São 2 casos de cegueira total, sendo que um se locomove com apoio de bengala e outro com apoio de cão-guia, além de 5 casos de visão monocular ou baixa visão. Todas as pessoas surdas usavam prótese auditiva e eram oralizados em língua portuguesa. Quanto à origem da deficiência, $60 \%(n=15)$ deve-se a doenças/ acidentes e $40 \%(n=10)$ a condições congênitas ou relacionadas ao nascimento.

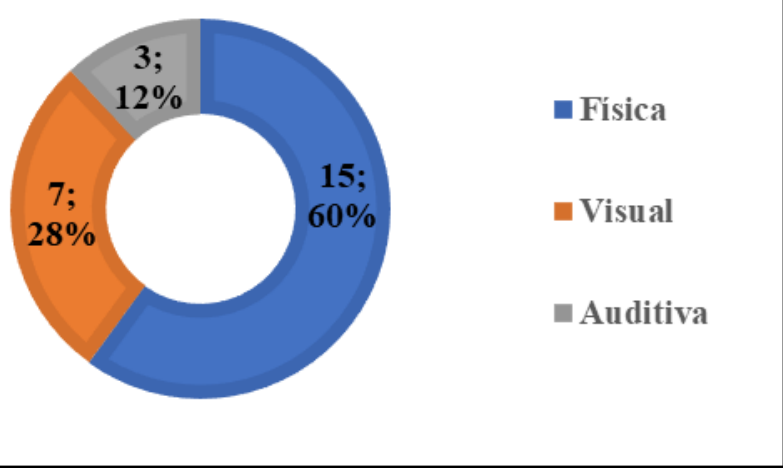

Figura 1: Perfil dos participantes em relação ao tipo de deficiência $(n=25)$.

Observa-se que essa amostra se situa no bojo da parcela minoritária de 6,7\% de PcD com nível superior de escolaridade, entre os 5,9\% de Trabalhadores com Deficiência (TcD) brasileiros empregados no serviço público civil ou militar e, ainda, entre os $2,6 \%$ de TcD que percebem mais de 10 salários mínimos mensalmente, conforme dados do Censo 2010 (Brasil, 2012).

\section{RESULTADOS E DISCUSSÕES}

$\mathrm{Na}$ análise de Classificação Hierárquica Descendente (CHD), foram classificados 885 dos $951 \mathrm{ST}$ identificados no corpus (93,06\%). A análise resultou em 32,960 ocorrências, 3,933 formas, 2,273 formas ativas e 6 classes, denominadas aqui de Núcleos Temáticos Estruturadores do Discurso (NTED), que participam em proporções bem equilibradas, variando de 15,5 a 18\%. A Figura 2 apresenta o dendograma com seus 6 NTEDs nominados de acordo com o tema estruturante e os respectivos percentuais de representação, em que se observam três 
núcleos independentes e outros três bem relacionados, como se pode visualizar melhor na Figura 2, a seguir:

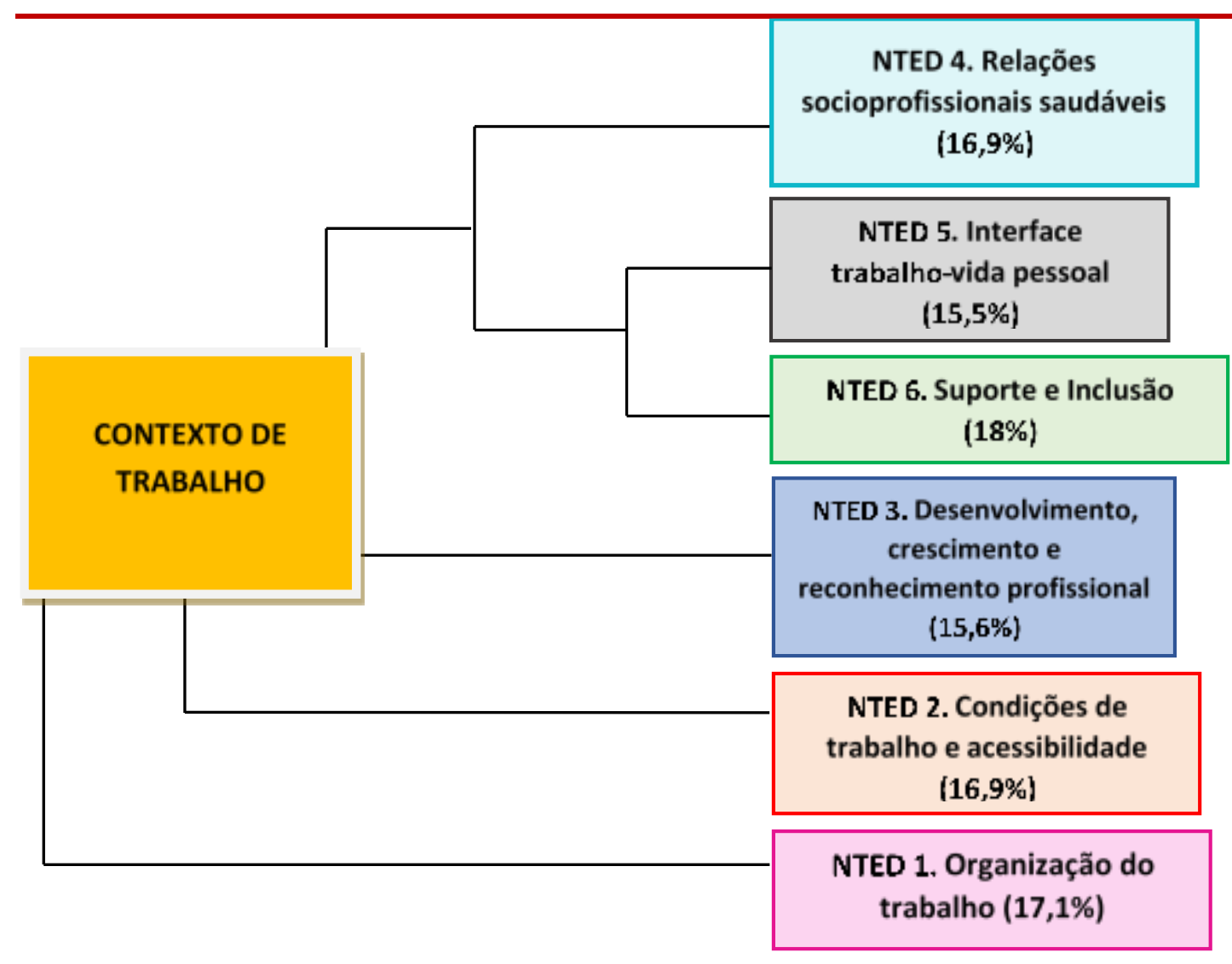

Figura 2: Dendograma com os 6 NTED representativos do contexto de trabalho, relacionados à percepção de Qualidade de Vida no Trabalho por servidores com deficiência, conforme percentual de incidência. 


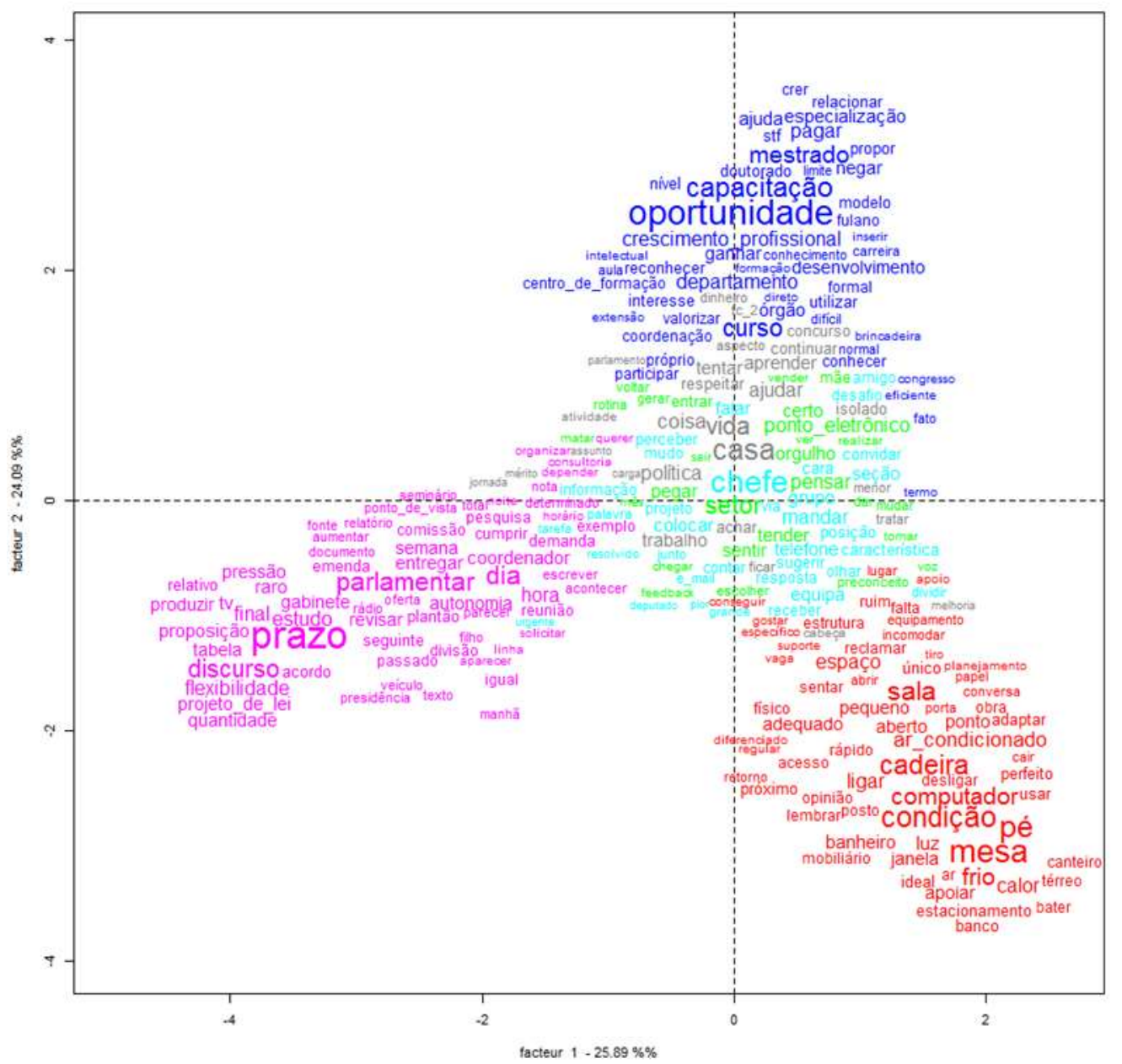

Figura 3: Análise fatorial de correspondência (AFC) de elementos do contexto de trabalho relacionados à representações de qualidade de vida no trabalho, por servidores com deficiência $(n=25)$.

NTED 1 - Organização do Trabalho - responde por 17,1\% do conteúdo classificado e refere-se à organização do trabalho, da rotina laboral, em relação a quantidade, prazos, horários, demandas, grau de autonomia e liberdade para realização das tarefas, prática de feedback das chefias. Observam-se representações mais positivas e de bem-estar quando há vivência de autonomia, liberdade, distribuição justa das tarefas, prazos exequíveis com possibilidade de realizar um trabalho com qualidade, boa gestão, feedback regular de desempenho, participação nas decisões. De outro lado, representações de espectro negativo, minoritárias nesta amostra quando esses aspectos não se concretizam, quando há pressão por entregas mais rápidas, quando há ausência de feedback. Aparece também crítica à forma de organização do trabalho, quanto à forma de realização da jornada e à impossibilidade do trabalho remoto. 
As formas mais frequentes foram: prazo $(\chi 2=117,39 ; \mathrm{p}<0,0001)$, dia $(\chi 2=62,29$; $\mathrm{p}<0,0001)$ e parlamentar $(\chi 2=60,39 ; \mathrm{p}<0,0001)$. Houve uma predominância significativa dos respondentes lotados na área legislativa $(\chi 2=68,73 ; p<0,0001)$.

A predominância de participação de servidores lotados na área legislativa provavelmente se deve ao fato de haver uma concentração de servidores de um mesmo contexto de trabalho, com organização de trabalho similar em que esses aspectos da rotina foram muito mencionados. Ademais, o processo legislativo orienta-se pela cadência dos prazos e pelo trabalho parlamentar, daí a força desses léxicos neste núcleo.

Encontra-se respaldo na literatura associações de bem-estar e percepção de QVT à autonomia e liberdade para organizar o trabalho, à divisão justa de tarefas, a prazos exequíve is, à satisfação com a forma de gestão (Antloga et al, 2016; Guimarães Júnior \& Macêdo, 2015) e de mal-estar relacionado à ausência de flexibilidade, de autonomia, de margem de manobra, à sobrecarga e a pressão por prazos (Fernandes, 2013; Ferreira, 2012; Ferreira \& Asmar, 2008;). De acordo com Kirkmeyer e Dougherty, citados por Ferreira e Assmar (2008), a sobrecarga de trabalho, queixa frequente dos trabalhadores, pode afetar a saúde, as atitudes sobre o trabalho o desempenho e os sentimentos sobre si próprio. São diversos os estudos, baseados em diferentes abordagens além da ergonomia, como a psicodinâmica do trabalho, a ergonomia e o estresse ocupacional, que têm identificado, consensualmente, relações entre fatores da organização do trabalho e o mal-estar no trabalho, segundo Fernandes e Vasques-Menezes (2012) citados por Fernandes (2013).

A ausência de feedback relacionado ao desempenho ou à qualidade do produto do trabalho, resultado do engajamento da subjetividade e da inteligência do trabalhador, implicando negativamente na dinâmica do reconhecimento, é associado na literatura à produção de sofrimento e mal-estar no trabalho (Dejours, 1993/2011; Mendes \& Araújo, 2012). Essa dinâmica pode ser comprometida pela própria forma de organização do trabalho, mediada por tecnologia da informação, no caso o uso de um software responsável por sistematizar, documentar e controlar de forma automática o processo de trabalho, que ocorre por meio de um fluxo de encaminhamentos - inputs e outputs - que tem por consequência o comprometimento da comunicação entre os atores, reduzida à sua dimensão formal e burocrática de registro das demandas e das respostas. Neste caso a medida da avaliação do produto do trabalho é a "não reclamação". A ausência de resposta é a resposta. Os sujeitos, entretanto, parecem estabelecer suas estratégias de mediação, para lidar com esse aspecto da organização do trabalho, que em certa medida frustra o exercício do reconhecimento, conforme se observa nas verbalizações transcritas a seguir. 
"Acho que o reconhecimento, ele é mais negativo, pela ausência de reclamação, ou seja, se não tem reclamação, você entende que tá bom."

"Reconhecimento que eu não vejo muito, para mim são esferas bem separadas, mas eu dou 10, eu não tenho nada a reclamar. Eu não espero reconhecimento pelo trabalho." (P.10)

NTED 2 - Condições de Trabalho e Acessibilidade - responde por 16,9\% do conteúdo classificado e refere-se às condições de trabalho, expressas por adequabilidade de elementos de infraestrutura física - espaço, mobiliário, equipamentos, temperatura, ventilação, iluminação - e de acessibilidade para o pleno exercício profissional, com condições de segurança e autonomia. Neste NTED coexistem representações positivas e negativas, com certa predominância de verbalizações negativas e queixas em relação a más condições de estrutura física e positivas, quanto a condições de acessibilidade.

De forma geral, representações positivas de condições de trabalho relacionam-se com representações de satisfação e bem-estar, o oposto também acontecendo - representações negativas quanto às condições de trabalho relacionadas com representações de mal-estar e insatisfação. Do mesmo modo, vivenciar condições favoráveis de acessibilidade aparece como fonte de bem-estar ou, no mínimo, de ausência de mal-estar. O suporte dado pela equipe de acessibilidade da organização é fonte de conforto e segurança no ambiente de trabalho.

Houve participação mais significativa do grupo do sexo feminino nesta classe $(\chi 2=$ 12,76; $\mathrm{p}=0,0001)$. As formas mais frequentes e mais significativas $(\mathrm{p}<0,0001)$ são: mesa $(\chi 2$ $=84,93)$, pé $\left(\chi^{2}=74,77\right)$, condição $\left(\chi^{2}=72,55\right)$, cadeira $\left(\chi^{2}=67,84\right)$ e sala $\left(\chi^{2}=60,23\right)$. A seguir, alguns exemplos de verbalizações:

\footnotetext{
"O único objeto novo é a minha mesa, que foi conseguida pelo pessoal da saúde do trabalho, tudo que tiver para falar do espaço físico e mobiliário eu acho horrível, não é legal não, o ruído é horrível por causa desse ar-condicionado barulhento." (P.22).

"Quanto às condições de trabalho e à acessibilidade, eu tenho acesso a todos os equipamentos que eu solicitei, o programa de acessibilidade me deu apoio desde a minha chegada aqui, me acompanhou, me ensinou os caminhos." (P.1)

"O espaço é muito pequeno, praticamente o espaço da mesa, do computador e da cadeira, mas isso não chega a ser exatamente um problema. Não compromete nem a qualidade de vida nem o trabalho." (P.13).
}

Foi encontrada uma participação mais significativa das verbalizações femininas neste NTED, o que demonstra que as mulheres se detiveram mais sobre esse tema. Além da perspectiva quantitativa, é possível notar uma preponderância de representações negativas e de mal-estar em suas falas, o que nos leva a interrogar se existe uma questão de gênero na percepção mais crítica da qualidade dos espaços laborais. De qualquer forma, é importante destacar, conforme salientaram Medeiros e Cunha-(2014) a diversidade da densidade 
populacional e da qualidade dos espaços no interior da organização, dependendo do setor de trabalho, o que pode, objetivamente, influenciar na avaliação subjetiva dos servidores sobre esse aspecto do contexto de trabalho.

A relação entre satisfação com condições de trabalho e percepção de bem-estar, e de outro lado, a insatisfação relacionada a mal-estar e impacto na percepção de QVT é achado frequente nas pesquisas com trabalhadores, no geral, (Albuquerque, Ferreira, Antloga, \& Maia, 2015; Branquinho, 2010; Do Carmo, 2014; Fernandes, 2013) e nas que envolvem trabalhadores com deficiência (TcD), em particular, destacando-se neste caso, os aspectos relacionados à acessibilidade e adaptação dos postos (Carvalho-Freitas, 2009; Carvalho-Freitas, Marques, \& Almeida, 2009; Neves-Silva, Prais, \& Silveira, 2015; Paiva, Bendassoli, \& Torres, 2015; Violante \& Leite, 2011), sendo que a insatisfação com esses aspectos, no limite, pode acabar motivando a saída do emprego (Scalabrin \& Campos, 2016). Também se têm encontrado indícios de correlação entre a percepção positiva do desempenho de TcD e as adaptações nas condições de trabalho (Carvalho-Freitas \& Marques, 2007).

\section{NTED 3 - Oportunidades de desenvolvimento e crescimento profissional - responde} por $15,6 \%$ do conteúdo classificado e remete às representações acerca das oportunidades de capacitação, aperfeiçoamento, desenvolvimento profissional e de crescimento e ascensão profissional. Em geral, há prevalência de percepções positivas e favoráveis quanto à existência de oportunidades de capacitação e desenvolvimento, o que é fonte de satisfação e bem-estar. Há ambivalência quanto à percepção de oportunidades de crescimento e ascensão profissional, com representações positivas e negativas. Os/as participantes creditam as dificuldades de crescimento profissional ou de ascensão, por meio de ocupação de funções comissionadas, à ausência de perspectivas relacionadas à área de atuação (área-meio), ou a aspectos característicos da própria carreira, ou, ainda, à questão da deficiência. No caso da deficiência, aparece como descrença no potencial da $\mathrm{PcD}$, referida mais fortemente pelos participantes cegos, o que se revela uma fonte importante de frustração e de mal-estar relacionado ao trabalho.

As formas mais frequentes foram: oportunidade $\left(\chi^{2}=96,91 ; p<0,0001\right)$, capacitação $(\chi 2$ $=64,52 ; \mathrm{p}<0,0001)$ e curso $(\chi 2=53,98 ; \mathrm{p}<0,0001)$. Houve uma predominância significativa dos respondentes do sexo masculino $\left(\chi^{2}=35,48, \mathrm{p}<0,0001\right)$ e uma participação não significativa dos servidores lotados na área administrativa $(\chi 2=2,34 ; p=0,13)$. Exemplos de verbalizações:

O resultado de predominância masculina no fator vai ao encontro de estudo de Zauli, Torres e Galinkin (2012), realizado com 1.320 servidores e servidoras da própria organização, 
entre 2005 e 2006, que encontrou que os servidores homens, mais que as mulheres, atribuem mais importância à oferta de treinamento e ao desenvolvimento de habilidades e competências .

Quanto à menor participação dos participantes da área administrativa pode haver alguma relação com o fato de o serviço mais burocrático e rotineiro desses setores, acabem por requerer menor necessidade de atualização contínua, tornando este aspecto do contexto de trabalho menos relevante.

Quanto aos resultados deste fator de forma geral, vão ao encontro de outras pesquisas realizadas com servidores públicos em geral (Andrade, 2011; Fernandes, 2013; Figueira, 2014) e com $\mathrm{TcD}$, que evidenciam satisfação com as oportunidades de capacitação, com a possibilidade de ter aprendizados significativos e manter-se em contínuo desenvolvimento, sendo este um aspecto relevante também na de percepção de QVT de TcD (Assunção, Carvalho-Freitas \& Oliveira, 2015; Carvalho-Freitas, 2009). Em outros estudos também se têm observado maior insatisfação com os aspectos relacionados a oportunidades de crescimento profissional, indicando a percepção de diferenças no tratamento em processos de promoção e queixas em relação à falta de equidade, sendo subestimados a priori sua capacidade e/ou seu potencial (Almeida, Carvalho-Freitas \& Marques, 2007; Assis \& Carvalho-Freitas, 2014; Carvalho-Freitas, 2009). Esse aspecto é muito nítido na verbalização a seguir:

\footnotetext{
"Reconhecimento e crescimento profissional, esse aspecto talvez seja o mais difícil. Um dos problemas é a falta de confiança na capacidade da pessoa de ser gestora, acham que a pessoa com deficiência... infelizmente, as pessoas não pagam para ver." $(P c D V)$
}

Ressalte-se que as queixas de dificuldades de 'promoção', que no contexto do serviço público refletem-se como a possibilidade de ocupação de funções comissionadas gerenciais ou de assessoramento, aparecem relacionadas diretamente à deficiência apenas na verbalização dos servidores cegos, em que a verbalização “infelizmente, as pessoas não pagam para ver” é bem ilustrativa e significativa. Bittencourt e Fonseca (2011) identificaram que a pessoa com deficiência visual apresenta desvantagem em relação às outras pessoas, não somente pela condição da deficiência, como também pelo preconceito e pela falta de informações quanto às suas potencialidades.

A relação indireta tem a ver com a jornada especial conferida às PcD. Quando se analis a a verbalização no contexto referido, em que há presença de qualificação técnica compatível e a ocorrência de oportunidades, em que colegas contemporâneos, com formação similar, foram indicados para assumir postos dessa natureza, é de se investigar se realmente não está ocorrendo uma desconsideração pelo potencial desse grupo. O mesmo participante explica assim: 


\begin{abstract}
"Também tem aquele negócio, 'eu não sou racista, ou machista', mas meu comportamento ... você não fala, mas você se comporta... age com preconceito, às vezes dá uma dor.... Mostrou que é preconceituo so, porque não confiou... não é com a deficiência visual, mas uma coisa de achar que, porque você não enxerga, então a cabeça não deve funcionar bem, é aquela ignorância preconceituosa. Aí você vê essas situações vindo de chefia, de gente com nível superior, com doutorado, não há explicação (...)".
\end{abstract}

Esse participante apresenta as características de um preconceito, que é sútil, velado, ausente no discurso, mas presente na prática, nas ações. Como se trata de relacionamento entre colegas, parece, portanto, estranho pensar em preconceito, então ele define a situação como "ignorância preconceituosa", mas ao mesmo tempo considera dificil de explicar e de entender, diante do paradoxo - como pensar em ignorância de alguém altamente escolarizado? Ribeiro e Ribeiro (2010, p. 123) descrevem assim a produção do preconceito, que ajuda a compreender o dilema vivido pelo participante em tela:

\begin{abstract}
"O preconceito se produz por uma predisposição perceptual, sócio historicamente construída, marcada pelo desconhecimento de uma rea lidade dada e por uma atitude desfavorável em relação a algo ou alguém, que não permite a apreensão global de fenômenos, estabelece uma diferenciação social e gera, por conseguinte, a legitimação de estereótipos e estigmas, que se interpõem na relação entre um dado sujeito e o outro sujeito, alvo de uma segregação. Assim, a opinião sobre o outro e a modalidade de relação com ele já estaria definida a priori pelo estereótipo que, como categoria descritiva simplificada baseada em crenças adquiridas, indica, de forma normativa, as possibilidades e impossibilidades dessa relação, além das expectativas acerca do outro." (grifos nossos).
\end{abstract}

Esse preconceito simbolizado pela desconfiança na capacidade da $\mathrm{PcD}$ não é achado incomum nos estudos da área (Abreu \& Moraes, 2012; Neves-Silva et al, 2015; Tanaka \& Manzini, 2005; Toldrá, 2013).

Importante destacar a consequência produzida - a dor. Estudos realizados no campo da EAA_QVT têm apontado relação entre falta de reconhecimento e de oportunidades de crescimento profissional e o mal-estar no trabalho (Branquinho, 2010; Do Carmo, 2014; Figueira, 2014). Ferreira (2011, p.43) afirma que "o mal-estar aparece inequivocamente associado à percepção de não-reconhecimento do trabalho sob as seguintes formas: postura das chefias; falta de incentivos; sentimento de injustiça; falta de perspectiva de ascensão e promoção profissional". Esses sentimentos de frustração, de tristeza relacionados ao não reconhecimento, tem como implicação o comprometimento da percepção de QVT.

NTED 4 - Relações socioprofisssionais saudáveis - Responde por 16,9\% do conteúdo classificado e reúne verbalizações acerca da qualidade e da importância das relações socioprofissionais com os pares, chefia e, eventualmente, usuários, incluindo aspectos de cooperação, sintonia, compartilhamento de informações, relações de amizade, espaço de 
diálogo e de discussão, e o quanto essas relações positivas contribuem para o desenvolvimento pessoal, profissional e para a melhoria dos processos (eficiência) e resultados do trabalho (efetividade).

As formas mais frequentes foram: chefe $\left(\chi^{2}=80,31 ; p<0,0001\right)$, mandar $\left(\chi^{2}=38,37\right.$; $\mathrm{p}<0,0001)$ e relacionamento $(\chi 2=35,61 ; \mathrm{p}<0,0001)$. Houve uma predominância significativa dos respondentes da área administrativa $(\chi 2=21,29 ; \mathrm{p}<0,0001)$.

A harmonia nas relações socioprofissionais, e a percepção de relações socioprofissio na is saudáveis é achado frequente nas pesquisas acerca de QVT com a população de servidores públicos em geral (Albuquerque et al, 2015; Antloga et al, 2016; Branquinho, 2010; Do Carmo, 2014) e também na de trabalhadores com deficiência (Carvalho-Freitas, 2009; Carvalho-Freitas et al, 2009, Carvalho-Freitas, Toledo, Nepomuceno, Suzano, \& Almeida, 2010). Ferreira e Antloga (2012) afirmam que as relações socioprofissionais desempenham um papel mediador ou compensatório quando existem problemas em outras dimensões, como as condições e organização do trabalho.

Nos resultados expostos também fica nítida a importância das relações socioprofissionais não apenas para o bom "ambiente" de trabalho e para o bem-estar, mas também para o aprendizado coletivo e para a melhoria de processos e da eficiência organizacional. Esses dados vão ao encontro do que Abbad e Borges-Andrade (2014) afirmam quanto à importância da cooperação e do clima de inovação para os processos de aprendizagem nas organizações.

NTED 5 - Interface trabalho-vida pessoal/social - Este núcleo temático, que responde por $15,5 \%$ dos conteúdos classificados, refere-se predominantemente às interrelações trabalho \& vida pessoal e social. Observa-se predomínio de satisfação quando se consegue organizar bem os tempos (tempo do trabalho e tempo da vida fora do trabalho), sem haver necessidade de levar trabalho para casa e quando se realiza um trabalho desafiador, significativo que possibilita incorporar e intercambiar aprendizados e experiências do trabalho e na vida pessoal. Eventualmente há impacto negativo do trabalho na subjetividade e nos outros domínios da vida, pela percepção de que o trabalho está invadindo a esfera pessoal, gerando ansiedade e malestar. Em geral, encontra-se percepção positiva de ser servidor da organização e orgulho de pertencer, no entanto também ocorre a observância de estereótipos externos negativos relacionados a essa imagem, eventualmente impactando negativamente a vida cotidiana e a autopercepção de servidor público do legis lativo.

As formas mais frequentes foram: casa $\left(\chi^{2}=69,9 ; \mathrm{p}<0,0001\right)$, vida $\left(\chi^{2}=56,1\right.$; $\mathrm{p}<0,0001)$, coisa $\left(\chi^{2}=39,7 ; \mathrm{p}<0,0001\right)$ e ajudar $(\chi 2=37,5 ; \mathrm{p}<0,0001)$. Houve uma 
predominância dos respondentes do sexo feminino nesta classe $(\chi 2=6,16 ; p=0,01)$. A seguir, algumas verbalizações representativas desse NTED:

\footnotetext{
"Então se não tomar cuidado o trabalho consome muito do seu tempo, aí você vai para casa praticamente para dormir, né?” (P. 14).

"Então assim, é perfeitamente equilibrado. Não levo trabalho para casa, não fico desesperada pensando em algum projeto, eu pessoalmente consigo equilibrar muito bem tudo que eu tenho que fazer.” (P. 12).
}

Essa valorização do equilibrio entre vida pessoal e laboral tem sido um achado recorrente nas pesquisas do campo da QVT e da deficiência (Assunção et al, 2015); que acaba sofrendo influência de aspectos relacionados à organização do trabalho, como a demanda e a jornada de trabalho.

Ferreira e Assmar (2008), citando Greenhaus e Buetell (1985) explicam que o conflito entre a vida pessoal e familiar baseia-se, fundamentalmente, em três aspectos: (1) no tempo quando o tempo de trabalho invade e prejudica o tempo familiar; (2) no comportamento quando as atitudes, valores e normas entre os dois papéis são incongruentes (ex: um trabalho que exige agressividade $\mathrm{x}$ necessidade de ser amoroso e colaborador em casa); no estresse pela transferência de reações emocionais suscitadas no trabalho para o ambiente doméstico. Nesta amostra, percebeu-se de maneira mais aparente os conflitos das categorias 1 e 3, na classificação desses autores.

A prevalência levemente significativa da participação feminina neste NTED pode indicar questão relacionada a gênero. Carneiro (2012) menciona que, em razão da divisão dos papéis sociais, as mulheres tendem a preferir dispor de mais tempo livre para o convívio familiar. Além disso, citando Estrade et al (2001) e Pinto (2003), afirma que a percepção de melhoria da qualidade de vida após redução de jornada em organizações francesas foi mais presente entre mulheres que entre homens, sobretudo nas que ocupavam posições gerenciais. Elas destacaram melhor uso do tempo para atividades domésticas, atividades de lazer, descanso e cuidados com a saúde.

É interessante também notar o impacto das novas tecnologias de informação e comunicação (NTIC) nessa interface trabalho-vida, que acaba por tornar esses limites cada vez mais tênues. $\mathrm{O}$ fato também de se trabalhar com conhecimento, em que a natureza da tarefa não é material (o servidor não carrega o trabalho para casa numa pasta, mas vai com ele em pensamento, ou surge quando menos espera) acaba conduzindo a uma extensão do tempo do trabalho e a uma fluidificação das linhas que separam trabalho e vida pessoal, como se evidencia nas verbalizações a seguir: 


\begin{abstract}
"Realmente hoje temos muita tecnologia, então acabamos ficando ligados 24 horas, é até exagerado, mas eu realmente procuro não misturar as bolas, acho que sua vida pessoalé sua vida pessoal, e trabalho é trabalho"(P.2).
\end{abstract}

"Porque às vezes, no trabalho, você está muito envolvido e, em casa, com a cabeça fresca vem a ideia”. (P.15).

Ferreira $(2008,2012)$ têm apontado e discutido sobre as metamorfoses do mundo do trabalho, que incluem a mediação das NTIC e como elas têm impactado a percepção de QVT, quais as estratégias que os trabalhadores utilizam para se "proteger" dessa "invasão" e manter o equilibrio entre os tempos e espaços de cada dimensão da vida.

NTED 6 - Suporte e inclusão - representa 18\% do conteúdo classificado e reúne elementos de suporte organizacional e social de apoio ao trabalho, inclusive no que tange à compreensão de peculiaridades ou de limitações relacionadas à deficiência. Observam-se representações positivas e bem-estar quando existe compreensão, tolerância, suporte, dimensionamento equilibrado e justo das demandas e das equipes de trabalho, quando o servidor é reconhecido pelo que é, pelos resultados que apresenta, a despeito da deficiência; quando a chefia oferece apoio, suporte e promove a inclusão. De outro lado, representações negativas e mal-estar quando isso não ocorre, ou ainda, quando o oposto acontece.

As formas mais frequentes foram: setor $\left(\chi^{2}=54,01 ; p<0,0001\right)$, vida $\left(\chi^{2}=56,1\right.$; $\mathrm{p}<0,0001)$, ponto-eletrônico $(\chi 2=35,61 ; \mathrm{p}<0,0001)$ e pensar $(\chi 2=34,49 ; \mathrm{p}<0,0001)$. Houve uma predominância dos respondentes do sexo feminino $(\chi 2=6,16 ; p=0,01)$.

\footnotetext{
"Todo mundo no começo tem um certo choque, ai depois que passam a conviver comigo, trabalharjunto, falam que não conseguem me ver como deficiente. Então é legal saber que a pessoa conseguiu te enxergar para além da deficiência.”(P.3).
}

"Eu já tive problemas, hoje eu não tenho, porque as pessoas tiveram que entender. $E$ quando precisa, também o meu chefe ele é compreensivo, e ele é assertivo com as pessoas, ele fala." (P. 17).

Os achados aqui se coadunam com os de Paiva et al (2015) que verificarám o mal-estar e o comprometimento dos sentidos do trabalho quando ocorrem situações de incompreensão de colegas de trabalho e relacionadas a dificuldades de se pronunciar em situações de grupo. Os autores consideram que as situações de impedimento e superação podem estar presentes em quaisquer outros contextos e com pessoas sem qualquer tipo de deficiência e que a deficiência, apesar de geradora de dificuldades na realização da atividade de trabalho, aparece como um impedimento superável, que não inviabilizava a realização da atividade, mas que demanda alguns esforços adicionais da pessoa e dos seus pares, bem como do auxílio de tecnologias adaptativas, que se relacionam no caso desse núcleo temático às questões de suporte e inclusão. 
Tette, Carvalho-Freitas e Oliveira (2014) e Suzano, Carvalho-Freitas, Tette e Brighenti (2016) também verificaram que os fatores de suporte informacional e instrumental estão relacionados com o significado do trabalho concreto para os $\mathrm{TcD}$, restando evidente a necessidade de se considerar esses aspectos de contexto organizacional para uma significação mais positiva do trabalho para os TcD.

Esses resultados também vão ao encontro dos estudos de campo de contato intergrupal, que têm confirmado que cooperação leva a maior amizade e menor preconceito entre as pessoas do grupo, do que situações e ambientes laborais que não promovam ou não requeiram interação cooperativa (Brewer, 2010).

Dejours (2015), sob a perspectiva da psicodinâmica do trabalho, destaca a necessidade da existência de espaços de deliberação formais e informais nas equipes de trabalho, para que se possa garantir a atividade de produção das regras do trabalho e a formação dos coletivos de trabalho. Para o autor, a cooperação decorre da possibilidade dos confrontos entre as opiniões e os modos operatórios de cada sujeito e, portanto, "o convívio é uma produção da atividade deôntica" (p.229) e o que possibilita a convivência, a consideração, a ajuda mútua, a solidariedade, a proteção ao isolamento, elementos fundamentais para a saúde mental no trabalho.

\section{CONSIDERAÇÕES FINAIS}

Os resultados obtidos e a discussão com base na literatura possibilitaram alcançar o objetivo de conhecer a avaliação de servidores com deficiência de uma organização do legislativo federal quanto a seu contexto de trabalho, em aspectos relacionados à Qualidade de Vida no Trabalho. Isso evidenciou seis fatores relacionados a (1) organização do trabalho; (2) condições de trabalho e acessibilidade; (3) oportunidades de desenvolvimento, crescimento e reconhecimento; (4) relações socioprofissionais; (5) interface trabalho e vida pessoal e (6) condições de suporte e inclusão. Coexistem representações de bem-estar e mal-estar, com certa predominância de representações de bem-estar, em termos quantitativos. Entretanto, as representações de mal-estar relacionadas a contradições presentes no contexto de trabalho são qualitativamente significativas e merecedoras de cuidado por parte da organização. De modo geral, observa-se bem-estar quando a organização do trabalho permite certo grau de autonomia, liberdade e flexibilidade, quando as relações interpessoais e com as chefias são saudáveis e harmoniosas, quando há espaço de fala e deliberação, quando existem oportunidades de crescimento profissional, aprendizagem e reconhecimento, quando há equilibrio entre os 
tempos do trabalho e da vida pessoal, quando existe compreensão, tolerância, suporte, dimensionamento equilibrado e justo das demandas e das equipes de trabalho, quando a chefia oferece apoio, suporte e promove a inclusão. O mal-estar se revela quando há sobrecarga de tarefas, pressão por prazos, desrespeito e desconsideração às necessidades individuais, percepção de injustiça e iniquidade nos critérios de indicação para ocupação de funções comissionadas, quando as opiniões não são consideradas e não há espaço de discussão, bem como nas situações em que as instalações físicas não fornecem o conforto esperado e as condições consideradas adequadas para a realização do trabalho. Os aspectos mais críticos em relação às condições físicas foram as das salas em subsolo sem iluminação e ventilação naturais, as salas que não permitem adequado controle da temperatura do ar-condicionado e as que apresentam alta densidade demográfica, destacando-se que estes aspectos não são restritos aos $\mathrm{ScD}$, mas uma condição geral, achados que corroboram os de Santos (2015). Em relação a aspectos relacionados à deficiência, os mais críticos foram a percepção de falta de oportunidades de ascensão, por meio da ocupação de funções comissionadas pelos servidores cegos e pelos servidores com jornada reduzida. As limitações de crescimento profissional relacionadas a questões da carreira e da natureza da área técnica constituem um desafio geral no serviço público e na organização em particular, e não são exclusividade dos $\mathrm{ScD}$.

Os aspectos aqui abordados podem auxiliar na construção de fatores relacionados ao construto de QVT em pesquisas futuras que abranjam a variável da deficiência como dimensão de análise. Gesser, Nuernberg e Toneli (2012, p. 557) discutem a relevância de a psicologia social crítica, "comprometida com a defesa dos direitos humanos e com a transformação social, integrar ao seu marco teórico os estudos sobre deficiência, considerando-a como uma categoria de análise e destacando-se a importância de tal opção para as políticas públicas". Da mesma forma, outras dimensões da diversidade, como gênero e raça, poderão auxiliar na maior compreensão sobre como essas variáveis se relacionam e influenciam nos processos sociais nas organizações, incluindo a promoção e percepção de QVT. Ainda nessa proposição de uma agenda futura de pesquisa, verifica-se a importância de se aprofundarem os estudos sobre a inserção das PcD no contexto do serviço público, bem como o de outros contextos ainda pouco pesquisados no Brasil, e o desenvolvimento de pesquisas mais amplas com maiores amostras, que permitam a realização de relações e inferências.

Quanto aos limites, destaca-se que o desenho de pesquisa privilegiou os servidores com deficiência, não contemplando a escuta de gestores e de colegas de trabalho, para se realizar um cotejamento das percepções. Outro limite decorre dos possíveis vieses, tanto da 
pesquisadora quanto dos participantes, considerando seus estados subjetivos e seus limites de memória (Gil, 2009).

Finalmente, destaca-se que o estudo contribui para desvelar um campo ainda pouco explorado da QVT de servidores com deficiência em organizações públicas, particularmente no contexto do legislativo, fornece pistas para novas investigações e subsídios aos gestores para mudanças organizacionais no contexto pesquisado.

\section{REFERÊNCIAS}

Abbad, G. S. \& Borges-Andrade, J. E. (2014). Aprendizagem humana em organizações do trabalho. In J. C. Zanelli, J. E. Borges-Andrade, \& A. V. B. Bastos. Psicologia, Organizações e Trabalho no Brasil. $2^{\mathrm{a}}$ ed. (Cap, 6, pp. 244-284). Porto Alegre: Artmed.

Abreu, M. V. \& Moraes, L. F. R. (2012). A qualidade de vida no trabalho de pessoas com deficiência: um estudo de caso em uma grande empresa do setor metalúrgico. Gestão OrgRevista Eletrônica de Gestão Organizacional. 10 (1) 84-104. Recuperado de: https//periodicos.ufpe.br/revistas/gestaoorg/article/view/21795/18379.

Albuquerque, V., Ferreira, M. C., Antloga, C. \& Maia, M. (2015). Revista Subjetividades, 15(2), 287-301. Disponível em: http://pepsic.bvsalud.org/pdf/rs/v15n2/12.pdf.

Almeida, L. A. D., Carvalho-Freitas, M. N., \& Marques, A. L. (2007). Relações entre as percepções das pessoas com deficiência sobre a satisfação e condições experenciadas no ambiente de trabalho. XIV Encontro Nacional da Associação Brasileira de Psicologia Social. Rio de Janeiro: ABRAPSO. Recuperado de: http://www.abrapso.org.br/siteprincipal/anexos/AnaisXIVENA/conteudo/pdf/trab_compl eto_27.pdf.

Andrade, P. P. (2011). Sentimento de (in)justiça na justiça: fatores (des)estruturantes de QVT sob a ótica dos servidores de um órgão do Poder Judiciário. (Dissertação de Mestrado). Universidade de Brasilia, Brasilia, DF, Brasil. Recuperado em http://repositorio.unb.br/handle/10482/10350.

Antloga, C., do Carmo, M., \& Takaki, K. (2016). O que é qualidade de vida no trabalho? Representações de trabalhadores de um instituto de pesquisa. Trabalho (En)Cena, 1(1), 132 142.

Recuperado de: https:/sistemas.uft.edu.br/periodicos/index.php/encena/article/view/2392.

Assis, A. M. \& Carvalho-Freitas, M. N. (2014). Estudo de caso sobre a inserção de pessoas com deficiência numa organização de grande porte. REAd. Revista Eletrônica de Administração, 20(2), 496-528. https://dx.doi.org/10.1590/1413-2311022201342126.

Assunção, R. V., Carvalho-Freitas, M. N., \& Oliveira, M. S. (2015). Satisfação no trabalho e oportunidades de desenvolvimento da carreira entre profissionais com deficiência. Revista Psicologia Organizações e Trabalho, 15(4), 340-351. Recuperado de: https $/ / d x . d o i . o r g / 10.17652 / \mathrm{rpot} / 2015.4 .556$. 
Bahia, M. S. (2006). Responsabilidade Social e Diversidade nas Organizações: contratando pessoas com deficiência. Rio de Janeiro: Qualitymark.

Bittencourt, Z. Z. L. C., \& Fonseca, A. M. R. (2011). Percepções de pessoas com baixa visão sobre seu retorno ao mercado de trabalho. Paidéia, 21(49), 187-195. Recuperado de:https://dx.doi.org/10.1590/S0103-863X2011000200006.

Bortman, D., Locatelli, G., Bandini, M., \& Rebelo, P. (2015). A inclusão de pessoas com deficiência: o papel de médicos do trabalho e outros profissionais de saúde e segurança. Curitiba, PR: ANAMT - Associação Nacional de Medicina do Trabalho. Disponível em: http://www.anamt.org.br/site/upload_arquivos/arquivos_diversos_185201614394870554 $\underline{75 . p d f}$.

Branquinho, N.G.S. (2010). Qualidade de vida no trabalho e vivências de bem-estar e malestar no trabalho em professores da rede pública municipal de Unaí/MG. (Dissertação de Mestrado). Universidade de Brasilia, Brasilia, Brasil. Recuperada em: http://repositorio.unb.br/hand le/10482/6929.

Brasil (2012). Cartilha do Censo 2010 - Pessoas com Deficiência. Luiza Maria Borges Oliveira. Secretaria de Direitos Humanos da Presidência da República (SDH/PR). Secretaria Nacional de Promoção dos Direitos da Pessoa com Deficiência (SNPD). Coordenação-Geral do Sistema de Informações sobre a Pessoa com Deficiência. Brasília: SDH-PR/SNPD. Recuperado de: http://www.pessoacomdeficiencia.gov.br/app/sites/default/files/publicacoes/cartilhacenso-2010-pessoas-com-deficienciareduzido.pdf.

Brewer, M. B. (2010). Intergroup Relations. In R. F. Baumeister \& E. J. Finkel. Advanced Social Psychology: the state of science. (Cap. 15, pp. 535 - 571). New York: Oxford University Press.

Camargo, B. V. \& Justo, A. M. (2013a). Tutorial para uso do software de análise textual IRAMUTEQ. Disponível em: http://www.iramuteq.org/documentation/fichiers/tutoriel-enportugais.

Camargo, B. V. \& Justo, A. M. (2013a). IRAMUTEQ: Um software gratuito para análise de dados textuais. Temas em Psicologia, 21(2), 513-518. Recuperado de: http:/pepsic.bvsalud.org/pdf/tp/v21 n2/v21 n2a16.pdf.

Carneiro, T. L. (2012). Jornada de trabalho em transformação: um amplo campo para a ergonomia da atividade. In M. C. Ferreira, C. P. Almeida, C. S. Antloga, E. L. Hostensky, \& R. M. Gonçalves (orgs). Diagnósticos em ergonomia no centro-oeste brasileiro: bemestar no trabalho, eficiência e eficácia em questão. Vol. I (Cap. 11, pp. 293-309). Brasília: Editora Universidade de Brasilia.

Carvalho-Freitas, M. N. (2009). Inserção e gestão do trabalho de pessoas com deficiência: um estudo de caso. Revista de Administraçâo Contemporânea, 13(spe), 121138. https:/dx.doi.org/10.1590/S1415-65552009000500009.

Carvalho-Freitas, M. N., Leal, G. T., \& Souto, J. F. (2011). Deficiência e Trabalho: Literatura Cientifica Internacional. Pesquisas e Práticas Psicossociais, 6(1). 128-138. Recuperado de: http:/www.ufsj.edu.br/porta12-repositorio/File/revistalapip/volume6_n1/CarvalhoFreitas_et_al.pdf. 
Carvalho-Freitas, M. N., \& Marques, A. L. (2007). A inserção de pessoas com deficiência em empresas brasileiras: uma dimensão específica da diversidade nas organizações. In Anais eletrônicos do XXXI Encontro Anual da Associação Nacional de Pós-Graduação e Pesquisa em Administração. Rio de Janeiro: Associação Nacional de Pós-Graduação e Pesquisa em Administração. Recuperado de: http //www.anpad.org.br/admin/pdf/EORB879.pdf.

Carvalho-Freitas, M. N., Marques, A. L., \& Almeida, L. A. D. (2009). Pessoas com deficiência: comprometimento organizacional, condições de trabalho e qualidade de vida no trabalho. Gerais: Revista Interinstitucional de Psicologia, 2(2), 92-105. Recuperado de em http $/ /$ pepsic.bvsalud.org/scielo.php?script=sci_arttext\&pid=S1983$82202009000200005 \& \operatorname{lng}=$ pt\&tlng=pt.

Carvalho-Freitas, M. N., Toledo, I. A., Nepomuceno, M. F., Suzano, J. C. C., \& Almeida, L. A. D. (2010). Socialização organizacional de pessoas com deficiência. Revista de Administração de Empresas, 50(3), 264-275. Recuperado de: https:/dx.doi.org/10.1590/S0034-75902010000300003.

Dejours, C. (1993/2011). Da psicopatologia à psicodinâmica do trabalho. In S. Lancman, \& L. I. Sznelwar (Orgs). Christophe Dejours: Da psicopatologia à psicodinâmica do trabalho. (Addendum, pp. 57-124). $3^{\mathrm{a}}$ ed. Brasilia: Paralelo 15.

Dejours, C. (2015). Organização do trabalho e saúde mental: quais são as responsabilidades do manager? In: Macedo, K. B. (org). O diálogo que transforma: a clínica psicodinâmica do trabalho. (Cap. 9, pp. 223-233). Goiânia: Ed. Da PUC Goiás.

Demo, P. (2000). Metodologia do conhecimento científico. São Paulo: Atlas.

Do Carmo, M. (2014). “Tribunal da cidadania?! Prá quem?!”: Qualidade de vida no trabalho em um órgão do poder judiciário brasileiro. (Dissertação de Mestrado). Universidade de Brasilia, Brasilia, DF Brasil. Recuperada de: http://repositorio.unb.br/bitstream/10482/17111/1/2014_MarinaMaiaDoCarmo.pdf.

Fernandes, L. C. (2013). “Estamos o tempo todo enxugando gelo”: Qualidade de Vida no Trabalho e Vivências de Bem-estar e Mal-estar em um órgão do Poder Judiciário. (Dissertação de Mestrado). Universidade de Brasilia, Brasîlia, DF, Brasil, 2014. Recuperada de: http//repositorio.unb.br/handle/10482/13715.

Ferreira, M. C. (2011). "Chegar feliz e sair feliz do trabalho": aportes do reconhecimento no trabalho para uma ergonomia aplicada à qualidade de vida no trabalho. In A. M. Mendes (Org). Trabalho e saúde: o sujeito entre emancipação e servidão. $\left(1^{\mathrm{a}} \mathrm{ed} .2008 .3^{\mathrm{a}}\right.$ reimp, Cap. 3, pp. 40-53). Curitiba: Juruá Editora.

Ferreira, M. C. (2012). Qualidade de vida no trabalho: uma abordagem centrada no olhar dos trabalhadores. ( $2^{\mathrm{a}}$ ed.) Brasilia: Paralelo 15.

Ferreira, M. C. \& Antloga, C. S. (2012). Ergonomia da Atividade. In M. C. Ferreira, C. P. Almeida, C. S. Antloga, E. L. Hostensky, \& R. M. Gonçalves (orgs). Diagnósticos em ergonomia no centro-oeste brasileiro: bem-estar no trabalho, eficiência e eficácia em questão. (Vol. I, Cap. 1, pp. 13-54). Brasilia: Editora Universidade de Brasîlia. 
Ferreira, M. C. \& Assmar, E. M. L. (2008). Fatores ambientais de estresse ocupacional e Burnout: tendências tradicionais e recentes de investigação. In A. Tamayo (Org.). Estresse e cultura organizacional. (Cap. 1, pp. 21-73). São Paulo: Casa do Psicólogo: All Books.

Figueira, T. G. (2014). Bem-estar, mal-estar e qualidade de vida no trabalho em uma Instituição Pública Brasileira. (Tese de Doutorado). Universidade de Brasillia, Brasília, DF, Brasil. Recuperado de: http://repositorio.unb.br/handle/10482/16074.

Garcia, V. G. (2014). Panorama da inclusão das pessoas com deficiência no mercado de trabalho no Brasil. Trabalho, Educação e Saúde, 12(1), 165-187. Recuperado de: http://dx.doi.org/10.1590/S1981-77462014000100010.

Gesser, M., Nuernberg, A. H., \& Toneli, M. J. F. (2012). A contribuição do modelo social da deficiência à psicologia social. Psicologia \& Sociedade, 24(3), 557-566. Recuperado de: http://www.scielo.br/pdf/psoc/v24n3/09.pdf.

Goldenberg, M. (2009). A arte de pesquisar: como fazer pesquisa qualitativa em Ciências Sociais. Rio de Janeiro: Record.

Guimarães Júnior, E. H. \& Macêdo, K. B. (2015). Uma nova doutrina de gestão baseada na psicodinâmica do trabalho. In: Macedo, K. B. (org). O diálogo que transforma: a clínica psicodinâmica do trabalho. (Cap. 12, pp. 276-296). Goiânia: Ed. Da PUC Goiás.

Hanashiro, D. M. M., Torres, C. V., Ferdman, B. M., \& D’Amario, E. Q. (2011). Medindo Inclusão no Ambiente Organizacional: Uma Visão "Emic" da Escala de Comportamento Inclusivo. XXXV Encontro da ANPAD. Rio de Janeiro: Brasil. Recuperado de: http://www.anpad.org.br/admin/pdf/GPR2378.pdf.

Lei n. 13.146, de 6 de julho de 2015. Institui a Lei Brasileira de Inclusão da Pessoa com Deficiência (Estatuto da Pessoa com Deficiência). Recuperado de http:/www.planalto.gov.br/ccivil_03/_ato2015-2018/2015/lei/113146.htm.

Medeiros, V. A. S. \& Cunha, I. R. M. (2014). Plano Diretor de uso dos espaços: caderno técnico 01. Brasîlia: Câmara dos Deputados, Edições Câmara. Recuperado de: http://bd.camara.gov.br/bd/hand le/bdcamara/17699.

Mendes, A. M. \& Araújo, L. K. R. (2012). Clínica psicodinâmica do trabalho: o sujeito em ação. Curitiba: Juruá.

Neves-Silva, P.; Prais, F. G., \& Silveira, A. M. (2015). Inclusão da pessoa com deficiência no mercado de trabalho em Belo Horizonte, Brasil: cenário e perspectiva. Ciência \& Saúde Coletiva, 20(8), 2549-2558. Recuperado de: http//dx.doi.org/10.1590/1413$\underline{81232015208.17802014 .}$

Paiva, J. C. M., Bendassolli, P. F., \& Torres, C. C. (2015). Sentidos e significados do trabalho: dos impedimentos às possibilidades do trabalho de pessoas com deficiência. Estudos $e$ Pesquisas em Psicologia, 15(1), 218-239. Recuperado de: http://pepsic.bvsalud.org/pdf/epp/v15n1/v15n1a13.pdf.

Ribeiro, M. A., \& Ribeiro, F. (2010). Gestão organizacional da diversidade: estudo de caso de um programa de inclusão de pessoas com deficiência. In M. N. Carvalho-Freitas, \& A. L. 
Marques (Orgs), Trabalho e Pessoas com Deficiência: Pesquisas, Práticas e Instrumentos de Diagnóstico. $2^{\mathrm{a}}$ reimp. (pp. 122-141). Curitiba: Juruá.

Santos, M. C. (2015). Trabalhadores e o Ambiente de Trabalho no Poder Legislativo Federal Brasileiro: Edifício Doente ou Edifício Adoecedor? (Dissertação de Mestrado). Centro de Formação, Treinamento e Aperfeiçoamento da Câmara dos Deputados, Brasilia, DF, Brasil. Recuperado de: http://bd.camara.gov.br/bd/handle/bdcamara/25585.

Sassaki, R. K. (2010). Inclusão: Construindo uma sociedade para todos. (8 ${ }^{\mathrm{a}}$. ed.) Rio de Janeiro: WVA.

Scalabrin, M., \& Campos, A. (2016). Caminhos desiguais: Um estudo da trajetória das Pessoas com Deficiência pela Educação e Mercado de Trabalho em um dos Estados mais Ricos da Federação. Cadernos de Pesquisa Interdisciplinar em Ciências Humanas, 16(108), 75-96. Recuperado de: https:/periodicos.ufsc.br/index.php/cadernosdepesquisa/article/view/1984$\underline{8951.2015 \mathrm{v} 16 \mathrm{n} 108 \mathrm{p} 75 .}$.

Suzano, J. C. C., Carvalho-Freitas, M. N., Tette, R. P. G., \& Brighenti, R. G. C. (2016). A Percepção dos Gestores Acerca do Desempenho de Trabalhadores com Diferentes Tipos de Deficiência. Interação em Psicologia, 18(3). 239-250. http://dx.doi.org/10.5380/psi.v18i3.35498.

Tanaka, E. D. O., \& Manzini, E. J. (2005). O que os empregadores pensam sobre o trabalho da pessoa com deficiência? Revista Brasileira de Educação Especial, 11(2), 273-294. https//dx.doi.org/10.1590/S1413-65382005000200008.

Tette, R. P. G, Carvalho-Freitas, M. N., \& Oliveira, M.S. (2014). Relações entre significado do trabalho e percepção de suporte para pessoas com deficiência em organizações brasileiras. Estudos de Psicologia, 19(3), 217-226.Recuperado de: https:/dx.doi.org/10.1590/S1413-294X2014000300007.

Toldrá, R. C. (2013). Inclusão no mercado de trabalho de pessoas com deficiência: contribuição para a transformação social. In:Simonelli, A.P. \& Rodrigues, D. S. (orgs). Saúde e trabalho em debate. Velhas questões novas perspectivas (Cap. 3, pp. 55-70). Brasilia: Paralelo 15.

Violante, R. R., \& Leite, L. P. (2011). A empregabilidade das pessoas com deficiência: uma análise da inclusão social no mercado de trabalho do município de Bauru, SP. Cadernos de Psicologia Social do Trabalho, 14(1) 73-91. Recuperado http://dx.doi.org/10.11606/issn.1981-0490.v14i1p73-91.

Watson, N. (2012). Researching disablement. In N. Watson, A. Roulstone \& C. Thomas (Eds). Routledge Handbook of Disability Studies. (Cap. 8, pp. 93-106). New York: Routledge. Taylor \& Francis Group. (E-book).

Zauli, A., Torres, C. V., \& Galinkin, A. L. (2012). Câmara dos Deputados: democracia e igualdade de oportunidades entre mulheres e homens? Cadernos de Psicologia Social do Trabalho, 15(1), 49-64. http://dx.doi.org/10.11606/issn.1981-0490.v15ilp49-64. 